\title{
Identification and Characterization of Russet on Snap Beans Caused by Plectosporium tabacinum
}

\author{
H. R. Dillard, A. C. Cobb, D. A. Shah, and K. E. Straight, Department of Plant Pathology, Cornell University, \\ New York State Agricultural Experiment Station, Geneva 14456
}

\begin{abstract}
Dillard, H. R., Cobb, A. C., Shah, D. A., and Straight, K. E. 2005. Identification and characterization of russet on snap beans caused by Plectosporium tabacinum. Plant Dis. 89:700-704.

Russet symptoms of unknown etiology are sporadically observed on snap bean (Phaseolus vulgaris) pods in New York and Maryland. Symptoms can render the whole crop unmarketable, and seem to appear when heavy rainfall occurs around harvest time. In 2000 and 2004, a microorganism not previously encountered was isolated from russet lesions on snap bean pods from commercial fields in Maryland and New York. Typical russet symptoms were produced on snap bean pods of $\mathrm{cv}$. Brio after inoculation with spores of the isolates. Koch's postulates were also fulfilled. The organism was identified as Plectosporium tabacinum (Van Beyma) M.E. Palm, W. Gams \& Nirenberg. A continuous 48 -h leaf wetness duration at 23 to $27^{\circ} \mathrm{C}$ was essential for rapid symptom development. Large $(11 \mathrm{~cm}$ long on average) snap bean pods were more susceptible to disease than smaller (pin) pods in cvs. Brio and Gold Mine. Light mechanical damage to the pods did not enhance infection. Four isolates of $P$. tabacinum (three from snap bean pods, one from zucchini) were inoculated onto large pods of the snap bean cvs. Brio, Gold Mine, and Hercules. All four isolates induced a russet on the pods, but the severity was significantly lower with the zucchini isolate.
\end{abstract}

Additional keywords: Cephalosporium tabacinum, Fusarium tabacinum, Microdochium tabacinum

Russet symptoms have been observed sporadically on snap bean (Phaseolus vulgaris) pods, but in 2000 severe outbreaks occurred on wax beans (cv. Gold Mine) in New York and on snap beans (cv. Brio) in Maryland (7). The beginning of symptom expression was associated with heavy rainfall or thunderstorms near the time of harvest. Symptoms usually began in the field, but on occasion apparently healthy pods developed symptoms in transit to market. Commercial producers described scenarios in which entire crops were rendered unmarketable by russet when harvest was disrupted for 2 days due to rainy weather, even though before the onset of rain the harvested pods appeared healthy and were marketable. Russet on beans lowered crop quality and consequently, when present at high levels, resulted in a $100 \%$ loss to some growers.

In the earlier literature, "russet" was used to describe the brownish to purplish

Corresponding author: H. R. Dillard

E-mail: HRD1@ @ornell.edu

Accepted for publication 22 February 2005.

DOI: 10.1094/PD-89-0700

(C) 2005 The American Phytopathological Society color observed on bean pod surfaces directly under mildewed (caused by Erysiphe spp.) tissues (23). By contrast, podflecking of snap beans caused by Alternaria alternata (Fr.) Keissler appears initially as small, irregular, water-soaked flecks and occurs on leaves, petioles, and pods, and the lesions tend to darken with age (2). The symptom descriptions for these pathogens do not adequately describe the russet symptoms that appeared on snap bean pods in New York and Maryland.

In this study, we demonstrate that russet on snap bean pods has a pathogenic basis, being incited by Plectosporium tabacinum (Van Beyma) M.E. Palm, W. Gams \& Nirenberg. This appears to be the first detailed report identifying $P$. tabacinum as a causal agent of russet on snap beans. A preliminary report has been made (7).

\section{MATERIALS AND METHODS}

Isolation of fungi from bean pods with russet symptoms. In 2000, isolations were made from snap bean (cv. Brio) pods with russet symptoms received from a commercial producer in Maryland. Approximately $2 \mathrm{~mm}^{2}$ thin slices of the epidermis from diseased areas on pods were made using a scalpel or razor blade. Tissue samples were then triturated in a drop of sterile distilled water on a glass microscope slide follow- ing a previously described procedure (14). Approximately $0.1 \mathrm{ml}$ of the liquid was pipetted onto potato dextrose agar (PDA) (Difco, Detroit, MI) amended with streptomycin and chloramphenicol (50 mg/liter) in $9-\mathrm{cm}$ plastic petri plates. Some plates were additionally amended with tetracycline $(50 \mathrm{mg} / \mathrm{liter})$. A sterile toothpick or bacterial loop was used to streak the suspension on the plate. Cultures were incubated at $23^{\circ} \mathrm{C}$ for $48 \mathrm{~h}$ and then subcultured onto PDA. The fungal isolates were stored on PDA plates at 3 to $5^{\circ} \mathrm{C}$ and at -10 to $-19^{\circ} \mathrm{C}$. Spores were also suspended in $15 \%$ glycerol in cryovials and frozen at $-80^{\circ} \mathrm{C}$ for long-term storage.

Bacteria were also isolated from symptomatic pod tissues, but colonies of similar type were recovered inconsistently. Moreover, pod symptoms were atypical of those we have encountered with other bacterial diseases in our experience. Therefore, bacterial isolates were not evaluated further in this study.

Snap beans in the northeastern and midwestern regions of the United States have been experiencing more severe epidemics due to aphid-transmitted viruses, and pod necrosis is one of the associated symptoms $(12,13)$. However, the symptom expression of russet on snap bean pods differs from the pod necrosis induced by viruses in the following ways: russet symptoms are more superficial; they are completely absent unless there is heavy rain a few days before harvest; no symptoms are seen on the leaves; and there is no apparent stunting of the plants as with virus infection.

Identification of $P$. tabacinum as a putative agent of russet. Three fungal isolates, recovered from the russet symptomatic pods of the cv. Brio sample from Maryland, were selected for further study: 985 (unidentified fungal species), 989 (Fusarium sp.), and 987 (Alternaria sp). Preliminary pathogenicity tests were done with these three isolates. For these tests, inoculum of isolate 985 was prepared by growing the isolate on PDA for 3 days at $25^{\circ} \mathrm{C}$. Spore suspensions were adjusted to an optical density reading of 1.0 to 2.0 on a spectrophotometer set at $600 \mathrm{~nm}$, equivalent to $1.0 \times 10^{7}$ to $2.0 \times 10^{8}$ spores per ml. Inocula for isolates 987 and 989 were prepared by growing them on PDA for 7 days 
at $25^{\circ} \mathrm{C}$. Suspensions consisting of spores and mycelial fragments were prepared from the colonies. Suspensions of isolate 987 contained $3.5 \times 10^{4}$ to $2.0 \times 10^{5}$ spores per ml plus 1.0 to $6.9 \times 10^{4}$ mycelial fragments. Suspensions of isolate 989 contained 1.3 to $2.3 \times 10^{7}$ spores per ml plus $1.2 \times 10^{4}$ to $1.0 \times 10^{5}$ mycelial fragments. Seven milliliters of each isolate suspension was atomized onto the leaves and pods of cv. Brio using a Preval sprayer. Control plants were sprayed with sterile distilled water. After inoculation, plants were placed in a mist chamber $\left(23\right.$ to $\left.27^{\circ} \mathrm{C}\right)$ and kept wet for the next $48 \mathrm{~h}$. Evaluations for symptom expression were made over the 18-day period postinoculation.

In these preliminary experiments (data not shown), only isolate 985 (out of the three selected) initiated any symptoms of disease. Spore suspensions with optical density readings less than 1.0 did not cause disease. Russet symptoms developed only on snap bean pods, and all pod sizes were affected. No symptoms were observed on the leaves or stems of any inoculated bean plants. Koch's postulates were fulfilled by the reisolation of an isolate similar (culturally and morphologically) to 985 from symptomatic pods. Misting continuously (mist generated using pneumatic nozzle assemblies [Spraying System Co., Wheaton, IL] with the air pressure for the water supply set at $2.8 \mathrm{~kg} \mathrm{~cm}^{-2}$ ) for at least 2 days was necessary for reproducing the rapid disease development observed in commercial fields.

Isolate 985 was identified by Walter Gams (Centraal bureau voor Schimmelcultures, The Netherlands) as P. tabacinum (Van Beyma) M.E. Palm, W. Gams \& Nirenberg. In 2004, we further isolated $P$. tabacinum from symptomatic snap bean pods (isolate 1038 from cv. Hystyle; isolate 1040 from cv. Hercules) from two different commercial fields in New York. Koch's postulates were met for both isolates 1038 and 1040 following the procedures described above.

Snap bean pods of the cvs. Brio, Gold Mine, and Hercules infected with isolates 985 and 1040 have been deposited with the Cornell Plant Pathology Herbarium under accession numbers CUP 67500, 67501, 67502, and 67503.

Pathogenicity of $P$. tabacinum isolates on snap bean. For further experimental work, we included an isolate of $P$. tabacinum from zucchini (isolate 991, which we purified from a PDA plate streaked with infected zucchini material and sent by S. Bost, Department of Entomology \& Plant Pathology, University of Tennessee). The pathogenicity of $P$. tabacinum isolates 985, 1038, and 1040 (from snap bean) and 991 (from zucchini) to large snap bean pods ( $>9.0 \mathrm{~cm}$ long, $11.2 \mathrm{~cm}$ on average) was examined in further detail. The experiment was designed as a two-way factorial ( $P$. tabacinum isolate by bean variety) replicated four times. Experimental units consisted of square pots $\left(121 \mathrm{~cm}^{2}\right)$ filled with Cornell soilless mix $\left(0.17 \mathrm{~m}^{3}\right.$ shredded sphagnum peat moss, $0.34 \mathrm{~m}^{3}$ vermiculite, $4.5 \mathrm{~kg}$ ground dolomitic limestone, $1.4 \mathrm{~kg} \mathrm{10-10-5}$ fertilizer) sown (four seeds per pot) to the snap bean cvs. Brio, Gold Mine, or Hercules. The seedlings were grown in a greenhouse held between 20 and $25^{\circ} \mathrm{C}$. At about 6 weeks of age, plants were prepared for inoculation by first removing dead, dying, or damaged leaves and blossoms, in addition to pods less than $9 \mathrm{~cm}$ in length. Plants were inoculated with spore suspensions of isolate $985,991,1038$, or 1040 , with inoculum being prepared as described above. A 7-ml suspension was atomized onto plants in each pot. Control plants were sprayed with sterile distilled water. After inoculation, the pots were arranged randomly on carts and placed in a walk-in mist chamber. The mist chamber temperature varied between 23 and $27^{\circ} \mathrm{C}$. Plants were misted continuously for $48 \mathrm{~h}$ as described above. Lighting was set at a 15-h day and 9-h dark period. Plants were kept in the mist chamber until they were rated, 3 to 4 days after inoculation. The experiment was conducted twice. Between experiments, the entire chamber and carts were surface disinfected with Green-Shield (Whitmire Micro-Gen, St. Louis, MO) at $3.9 \mathrm{ml} / \mathrm{liter}$.

Severity of russet on the pods was assessed visually on an ordinal 0 to 9 scale, where $0=$ no symptoms, $1=$ a few specks with up to $2 \%$ of the pod with russet symptoms, $2=2$ to $5 \%, 3=5$ to $10 \%, 4=10$ to $25 \%, 5=25$ to $50 \%, 6=50$ to $70 \%, 7=70$ to $90 \%, 8=90$ to $<100 \%, 9=100 \%$ of the pod surface covered with russet. Data were analyzed nonparametrically (20) using Proc Mixed of SAS (SAS Institute, Cary, NC). Preliminary data analysis showed that the results of both experimental runs were very similar, and so the data from both runs were combined for the final analysis. Relative treatment effects and their confidence intervals were calculated using the LD_CI macro (5).

Bean variety, pod size, and injury effects. The experimental design was a completely randomized three-way factorial replicated three times. The experiment was conducted three separate times. The factors were bean variety, pod size at inoculation, and wounding (either pods were wounded just before inoculation or not). Seedlings of the two bean cvs. Brio and Gold Mine were grown in the greenhouse (as described above). Plants were inoculated with spore suspensions of isolate 985 using the same procedure as before. Plants were inoculated at the pin (pod length between 2.5 and $5.0 \mathrm{~cm}$ ), medium (pods between 5.0 and $12.0 \mathrm{~cm} \mathrm{long),} \mathrm{or} \mathrm{large} \mathrm{(pods}$ $>12.0 \mathrm{~cm}$ long) pod stage. Prior to inoculation, senescent tissues and pods that were not the correct size for the given treatment were removed. We used pod size rather than age as the measure of pod growth stage to reflect the fact that commercial snap bean fields are harvested based on determinations of pod size, not age. Although pod age and size are obviously correlated, weather conditions after bloom can delay pod maturity by as much as 5 days. Wounding prior to inoculation (to simulate the effect of high winds) was done by holding an electric leaf blower (Paramount Wind Broom Model PB90-00, Allegretti \& Co., Chatsworth, CA), which generated an air velocity of about $225 \mathrm{~km}$ $\mathrm{h}^{-1}, 30$ to $46 \mathrm{~cm}$ from the side of the plants for $5 \mathrm{~min}$. Control plants (injured and uninjured) were sprayed with sterile distilled water. Severity of russet on the pods was assessed visually on the ordinal 0 to 9 scale described above. Data and results were consistent across runs, based on pre-

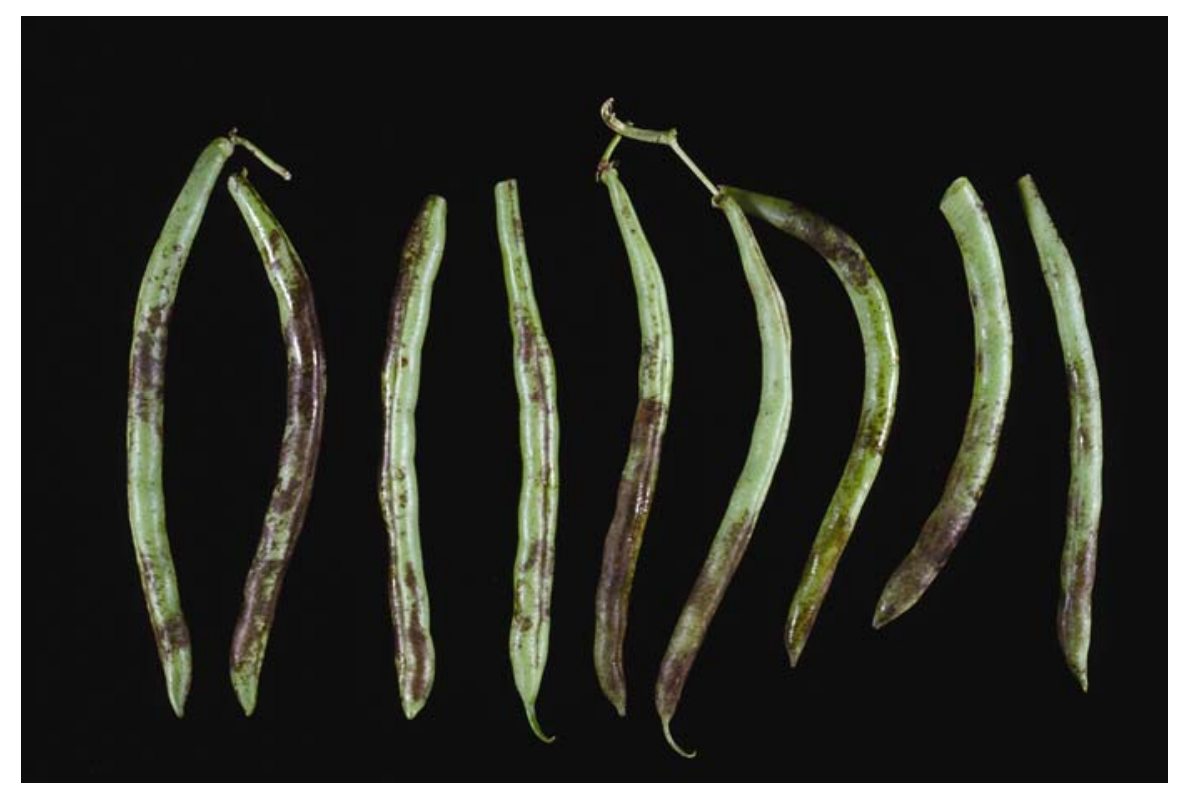

Fig. 1. Severe symptoms of russet on snap bean cv. Brio sampled from a commercial field in 2000. 
liminary analyses. Therefore, the data from each experimental run were pooled, and the combined dataset was analyzed as a three-way factorial using nonparametric methods (20). Relative treatment effects and their confidence intervals were calculated using the LD_CI macro (5).

\section{RESULTS}

Symptom expression. Russet symptoms observed in commercial fields of the cvs. Brio, Gold Mine, Hystyle, and Hercules were evident only on the pods and consisted of diffuse, superficial, light brown necrotic areas or flecks on the pods with undefined borders (Figs. 1 and 2). These symptoms were reproducible in the greenhouse when bean pods were inoculated

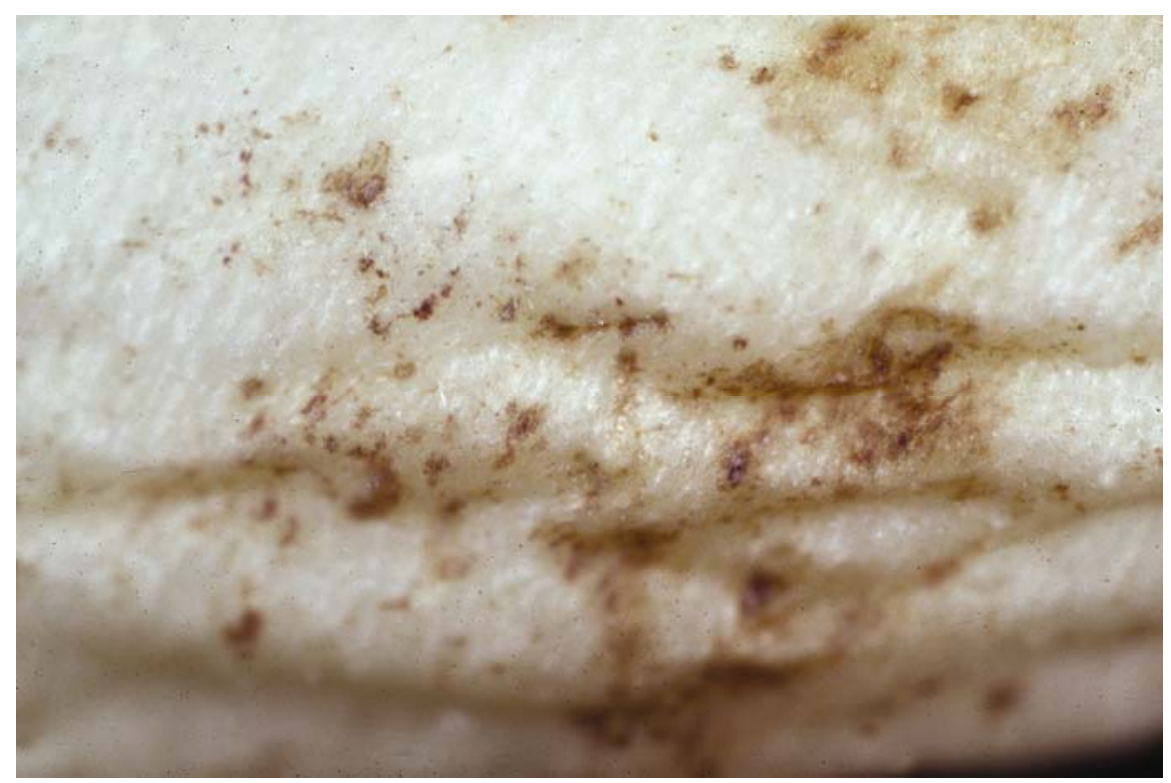

Fig. 2. Close-up of russet symptoms on snap bean pods of cv. Gold Mine sampled from a commercial field in 2000.

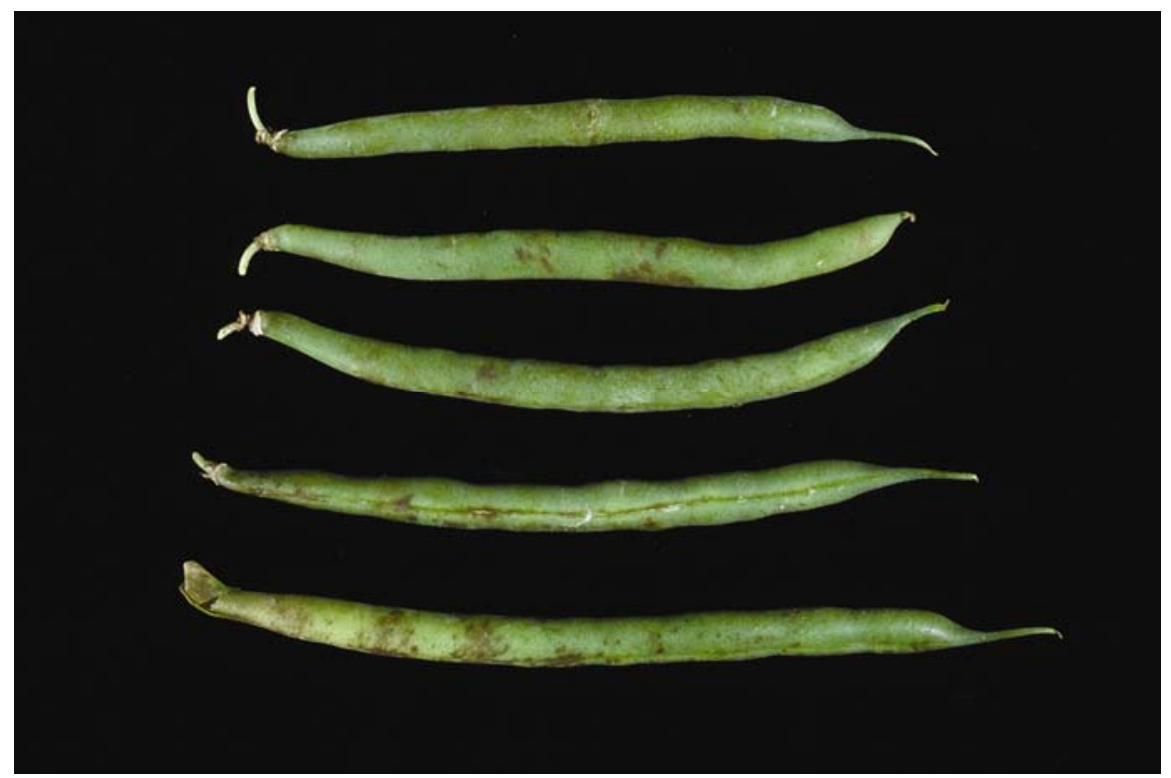

Fig. 3. Russet symptoms on snap bean pods (cv. Brio) after inoculation with isolate 985 of Plectosporium tabacinum. from symptomatic bean pod tissue (Fig. 3). Symptoms were often severe in the sutures of the pod, possibly due to accumulation of not confined to any one area of the pod, and the lesions varied in size and shape (Figs. 1 and 2).

Pathogenicity of $P$. tabacinum isolates on snap beans. When inoculated onto the bean varieties, all four isolates of $P$. tabacinum caused a russet on the pods (Table 1) that was significantly more severe than symptoms observed on control plants $(P<$ 0.0001). The low levels of russet-like symptoms observed on the controls were caused by undetermined effects associated with maintaining the plants in the mist with isolates of $P$. tabacinum obtained moisture. However, russet symptoms were

chamber, as $P$. tabacinum was not reisolated from the pods of control plants. There were no significant differences among the bean isolates $(985,1038,1040)$ in terms of the levels of russet they induced $(P>0.30)$, but all three induced significantly more russet than the $P$. tabacinum isolate 991 from zucchini $(P<$ 0.0001). Among the bean cultivars, no significant differences were observed in the levels of russet induced on cvs. Brio and Hercules $(P=0.8860)$, but the levels of russet that developed on cv. Gold Mine were significantly less than that observed on either Brio $(P=0.0001)$ or Hercules $(P$ $<0.0001$ ).

Bean variety, pod size, and injury effects. The severity of russet on bean pods generally increased with pod size at the time of inoculation (Table 2). Wounding the pods before inoculation had no effect on the amount of russet developing on pods $(P=0.4771)$. The response profiles of the two varieties were different (indicated by the significant variety by pod size interaction; $P<0.0001)$. The other interaction terms (two- and three-way) between the effects of variety, pod size, and damage status were not statistically significant $(P>$ $0.30)$. The significant variety-by-pod size interaction precludes the interpretation of variety or pod size main effects, and therefore comparisons of the responses to inoculation were made within each cultivar by statistical contrasts. For the cv. Brio, russet levels were significantly higher when pods were inoculated at the medium stage as opposed to the pin stage $(P<$ $0.0001)$, and at the large stage compared with the medium stage $(P<0.0001)$. However, for Gold Mine, although russet levels were significantly higher when pods were inoculated at the medium stage compared with the pin stage $(P<0.0001)$, the differences were not as apparent when inoculations were made at the large stage compared with the medium stage $(P=0.0442)$.

\section{DISCUSSION}

In this study, we show that the host range of $P$. tabacinum extends to snap bean. $P$. tabacinum was previously classified as Cephalosporium tabacinum Van Beyma, Microdochium tabacinum (Van Beyma) Arx (21), and Fusarium tabacinum (Van Beyma) W. Gams. A teleomorph, Plectosphaerella cucumerina (Lindfors) W. Gams, previously classified as Venturia cucumerina Lindfors, Plectosphaerella cucumeris Kleb., or Micronectriella cucumeris (Kleb.) C. Booth, is sometimes formed (17).

In the earlier literature, $P$. tabacinum was identified as a common saprophyte in decaying plant material, seeds, and arable soils (8). It is also a facultative parasite, having been documented from a wide range of plants, including soybean (Glycine $\max (\mathrm{L}$.) Merr.), tomato (Lycopersicon esculentum Mill.), white lupine ( $\mathrm{Lu}$ - 
pinus termis Forsk.), sunflower (Helianthus annuus L.), sweet basil (Ocimum basilicum L.), and peanut (Arachis hypogaea L.) $(6,10,11,16,18,22,24)$, and appears to have a worldwide distribution $(17,19)$. Symptoms caused by $P$. tabacinum vary markedly among hosts. In recent years, $P$. tabacinum has become more visible in the United States as a new or squash, pumpkin, and zucchini (Cucurbita реро L. subsp. pepo $)(3,4,9,15)$. In the cucurbits, in contrast to what we found with snap bean, all plant parts can be affected, and vines may be defoliated or killed within a few weeks. As in snap bean, lesions on the fruits make them unmarketable. The ubiquitous distribution of $P$. tabacinum, its wide host range, and its ability to survive saprophytically are of concern to crop production. The organism appears to opportunistically parasitize plants under conducively wet conditions. sary to induce russet symptoms on the pods. Pods at any stage of development were susceptible to pathogen-induced rusemerging pathogen on yellow summer

Prolonged moist conditions were neces-

set. Our experimental findings that more mature pods are at an increased risk of russet incited by $P$. tabacinum when they remain wet for a relatively long time is of significant concern, and is in agreement with grower observations of the rapid appearance of the disease on mature pods just when they are ready for harvest. In affected fields, pods appeared healthy when checked for maturity a few days to a week prior to projected harvest date. In those same fields, about 3 days before harvest there was heavy rain. About 3 days after the rains, symptoms of russet appeared on the pods, making them unmarketable. Yet, in some cases, nearby bean fields at similar stages of maturity that were missed by thunderstorms were not affected by russet.

It appears that there may be some varietal differences in the susceptibility of mature pods to $P$. tabacinum, as indicated by the responses of cvs. Brio, Gold Mine, and Hercules. However, the experimental results also suggest that varieties may differ in terms of the severity of russet in relation to the stage of pod development at the time

Table 1. Median, mean rank $\left(\bar{R}_{i j}\right.$ ), and relative treatment effects $\left(\hat{p}_{i j}\right)$ along with $95 \%$ confidence intervals (CI) for snap bean pod russet severity ratings in relation to bean variety and isolate of Plectosporium tabacinum

\begin{tabular}{llcccc}
\hline Variety & Isolate $^{\mathbf{a}}$ & Median $^{\mathbf{b}}$ & $\overline{\boldsymbol{R}}_{\boldsymbol{i j} \boldsymbol{\bullet}}$ & $\hat{\boldsymbol{p}}_{\boldsymbol{i j}}$ & $\mathbf{9 5 \%}$ CI for $\hat{\boldsymbol{p}}_{\boldsymbol{i j}}$ \\
\hline Brio & Control & 0.0 & 17.8 & 0.161 & $(0.122,0.215)$ \\
& 985 & 4.5 & 77.7 & 0.721 & $(0.631,0.794)$ \\
& 991 & 1.0 & 35.6 & 0.328 & $(0.270,0.393)$ \\
& 1038 & 2.0 & 70.5 & 0.654 & $(0.441,0.814)$ \\
\multirow{6}{*}{ Gold Mine } & 1040 & 5.0 & 81.6 & 0.758 & $(0.679,0.820)$ \\
& Control & 0.0 & 13.0 & 0.117 & $(0.103,0.133)$ \\
& 985 & 3.0 & 59.3 & 0.549 & $(0.411,0.679)$ \\
& 991 & 0.0 & 17.8 & 0.161 & $(0.099,0.259)$ \\
\multirow{6}{*}{ Hercules } & 1038 & 2.0 & 55.3 & 0.512 & $(0.436,0.588)$ \\
& 1040 & 3.0 & 59.4 & 0.551 & $(0.481,0.618)$ \\
& Control & 0.0 & 13.0 & 0.117 & $(0.103,0.133)$ \\
& 985 & 5.0 & 81.8 & 0.759 & $(0.654,0.836)$ \\
& 991 & 1.0 & 32.0 & 0.294 & $(0.272,0.318)$ \\
& 1038 & 5.0 & 78.8 & 0.732 & $(0.543,0.854)$ \\
& 1040 & 5.0 & 80.3 & 0.746 & $(0.578,0.855)$ \\
\hline
\end{tabular}

a Controls were sprayed with sterile distilled water. Isolates 985, 1038, and 1040 were obtained from snap bean pods. Isolate 991 was from zucchini.

${ }^{\mathrm{b}}$ Severity of russet on pods was assessed visually on an ordinal 0 to 9 scale, where $0=$ no symptoms and $9=100 \%$ of the pod surface covered with russet. of infection. For example, mature pods of cv. Gold Mine appeared to be less susceptible to infection by $P$. tabacinum than those of the other cultivars, but Gold Mine pods infected at the medium stage of growth were just as likely to develop russet as pods infected at a more mature stage of development.

Our study included an isolate of $P$. tabacinum obtained from zucchini. Interestingly, this isolate induced less severe russet on snap bean pods than those isolates obtained from infected bean pods from commercial fields. In another study (data not shown), we found that isolate 985 from snap bean did not cause russet in two summer squash varieties (Lemondrop and Senator), although significant levels of russet were induced on the plants by isolate 991 from zucchini. Based on our results, host specialization may occur within the $P$. tabacinum population. Further work is necessary to determine whether $P$. tabacinum populations are indeed differentiated accordingly. Other research suggests that the species may be genetically diverse (1). Further research is also warranted to determine if particular cropping sequences encourage growth of $P$. tabacinum populations and therefore increase the risk of russet in subsequent snap bean crops.

\section{ACKNOWLEDGMENTS}

We thank C. J. K. Wang and W. Gams for invaluable assistance in isolate identification. We thank G. Straight, M. C. Heidenreich, N. Call, E. Lippy, and D. Hurdle for technical assistance. This research was supported in part by the New York State Vegetable Research Association.

\section{LITERATURE CITED}

1. Abad, P., Pérez, A., Marqués, M. C., Vincente, M. J., Bruton, B. D., and García-Jiménez, J. 2000. Assessment of vegetative compatibility of Acremonium cucurbitacearum and Plectosphaerella cucumerina isolates from diseased melon plants. Bull. OEPP/EPPO Bull. 30:199-204.

2. Abawi, G. S., Crosier, D. C., and Cobb, A. C. 1977. Pod-flecking of snap beans caused by $A l$ ternaria alternata. Plant Dis. Rep. 61:901-905.

3. Babadoost, M. 2002. Plectosporium blight of pumpkins, a new fungal disease in Illinois. (Abstr.) Phytopathology 92:S5.

4. Bost, S. C., and Mullins, C. A. 1992. A blight

Table 2. Median, mean rank ( $\bar{R}_{i j k}$ ), and relative treatment effects ( $\left.\hat{p}_{i j k}\right)$ along with $95 \%$ confidence intervals (CI) for snap bean pod russet severity ratings in relation to bean variety, pod size at inoculation with Plectosporium tabacinum isolate 985 , and pod damage

\begin{tabular}{|c|c|c|c|c|c|c|}
\hline Variety & Pod size & Damage $^{a}$ & Median $^{\mathrm{b}}$ & $\bar{R}_{i j k}$. & $\hat{p}_{i j k}$ & $95 \%$ CI for $\hat{p}_{i j k}$ \\
\hline \multirow[t]{6}{*}{ Brio } & Pin & Undamaged & 1.5 & 22.3 & 0.182 & $(0.135,0.248)$ \\
\hline & Medium & Undamaged & 4.0 & 62.4 & 0.516 & $(0.428,0.603)$ \\
\hline & Large & Undamaged & 6.0 & 100.6 & 0.834 & $(0.734,0.895)$ \\
\hline & Pin & Damaged & 2.0 & 25.3 & 0.207 & $(0.157,0.274)$ \\
\hline & Medium & Damaged & 4.5 & 68.0 & 0.562 & $(0.462,0.657)$ \\
\hline & Large & Damaged & 5.0 & 96.7 & 0.802 & $(0.710,0.865)$ \\
\hline \multirow[t]{6}{*}{ Gold Mine } & Pin & Undamaged & 1.0 & 16.9 & 0.137 & $(0.092,0.210)$ \\
\hline & Medium & Undamaged & 5.0 & 86.9 & 0.720 & $(0.659,0.773)$ \\
\hline & Large & Undamaged & 5.0 & 77.7 & 0.643 & $(0.522,0.745)$ \\
\hline & Pin & Damaged & 1.0 & 28.0 & 0.229 & $(0.164,0.316)$ \\
\hline & Medium & Damaged & 5.0 & 89.8 & 0.744 & $(0.641,0.822)$ \\
\hline & Large & Damaged & 5.0 & 72.7 & 0.602 & $(0.487,0.705)$ \\
\hline
\end{tabular}

\footnotetext{
a Plants were damaged with a leaf blower to simulate injury by high winds in commercial fields.
}

${ }^{\mathrm{b}}$ Severity of russet on pods was assessed visually on an ordinal 0 to 9 scale, where $0=$ no symptoms and $9=100 \%$ of the pod surface covered with russet. 
of cucurbits caused by Microdochium tabacinum. Plant Dis. 76:861.

5. Brunner, E., Domhof, S., and Langer, F. 2002. Nonparametric Analysis of Longitudinal Data in Factorial Experiments. John Wiley \& Sons, New York.

6. Chen, W. D., Gray, L. E., Kurle, J. E., and Grau, C. R. 1999. Specific detection of Phialophora gregata and Plectosporium tabacinum in infected soybean plants using polymerase chain reaction. Mol. Ecol. 8:871-877.

7. Dillard, H. R., and Cobb, A. C. 2004. Russet on snap beans, a new disease caused by Plectosporium tabacinum in New York and Maryland. (Abstr.) Phytopathology 94:S26.

8. Domsch, K. H., Gams, W., and Anderson, T. H. 1980. Compendium of Soil Fungi. Vol. 1. Academic Press, London.

9. Evans, T. A., Rouse, R. J., Ringer, C. E., Kantzes, J. G., and Dillard, H. R. 1995. Occurrence of Microdochium blight of squash on the Delmarva peninsula. (Abstr.) Phytopathology 85:1195.

10. Garibaldi, A., Gullino, M. L., and Minuto, G. 1997. Diseases of basil and their management. Plant Dis. 81:124-132.

11. Harrington, T. C., Steimel, J., Workneh, F., and
Yang, X. B. 2000. Molecular identification of fungi associated with vascular discoloration of soybean in the north central United States. Plant Dis. 84:83-89.

12. Larsen, R. C., and Eastwell, K. C. 2004. Identification of Clover yellow vein virus as the causal agent of pod necrosis ("chocolate pod") in snap bean. (Abstr.) Phytopathology 94:S57.

13. Larsen, R. C., Grau, C. R., Eastwell, K. C., Mondjana, A. M., Miklas, P. N., and Stevenson, W. R. 2002. A virus disease epidemic of snap bean occurring in the Great Lakes region of the United States. (Abstr.) Phytopathology 92:S44.

14. Matteson Heidenreich, M. C., Corral-Garcia, M. R., Momol, E. A., and Burr, T. J. 1997. Russet of apple fruit caused by Aureobasidium pullulans and Rhodotorula glutinis. Plant Dis. 81:337-342.

15. Mullen, J. M., and Sikora, E. J. 2003. First report of plectosporium blight on pumpkin caused by Plectosporium tabacinum in Alabama. Plant Dis. 87:749.

16. Odunfa, S. A. 1979. Fusarium species associated with groundnut fruit and soil in Nigeria. Trans. Br. Mycol. Soc. 72:342-344.

17. Palm, M. E., Gams, W., and Nirenberg, H. I.
1995. Plectosporium, a new genus for Fusarium tabacinum, the anamorph of Plectosphae rella cucumerina. Mycologia 87:397-406.

18. Pascoe, I. G., Nancarrow, R. J., and Copes, C. J. 1984. Fusarium tabacinum on tomato and other hosts in Australia. Trans. Br. Mycol. Soc. 82:343-345.

19. Seifert, K. A. 1996. Plectosporium tabacinum Can. J. Plant Pathol. 18:309-311.

20. Shah, D. A., and Madden, L. V. 2004. Nonparametric analysis of ordinal data in designed factorial experiments. Phytopathology 94:33-43.

21. von Arx, J. A. 1984. Notes on Monographella and Microdochium. Trans. Br. Mycol. Soc. 83:373-374.

22. Youssef, Y. A., El-Tarabily, K. A., and Hussein, A. M. 2001. Plectosporium tabacinum root rot disease of white lupine (Lupinus termis Forsk.) and its biological control by Streptomyces species. Phytopathol. Z. 149:29-33.

23. Zaumeyer, W. J., and Thomas, H. R. 1957. A monographic study of bean diseases and methods for their control. U.S. Dep. Agric. Tech. Bull. No. 868

24. Zazzerini, A., and Tosi, L. 1987. New sunflower disease caused by Fusarium tabacinum Plant Dis. 71:1043-1044. 